\title{
A OPRESSÃO SIMBÓLICA E A RESPOSTA DO OPRIMIDO*
}

\author{
LA OPRESIÓN SIMBÓLICA Y LA RESPUESTA DEL OPRIMIDO
}

THE SYMBOLIC OPPRESSION AND THE RESPONSE OF THE OPPRESSED

\author{
RAQUEL ROCHA DE QUEIROZ E SOUSA** \\ ANDREY DA SILVA BRUGGER***
}

Recibido: 20 de agosto de 2017 - Aceptado: 20 de septiembre de 2017 - Publicado 31 julio de 2018 DOI: $10.24142 /$ raju.v13n26a8

\section{Resumo}

O presente trabalho tem o objetivo de conectar a teoria criada por Pierre Bourdieu sobre a violência simbólica e o texto de Audre Lorde, The use of anger: women responding to racism do seu livro Sister Outsider; demonstrando a importância do debate sobre a relação entre dominante e dominado a partir do viés racial, tema abordado por

\footnotetext{
* Trabalho desenvolvido no âmbito do Projeto de Iniciação científica coordenado pelo Professor Andrey da Silva Brugger, no Centro Universitário Estácio Juiz de Fora, intitulado "Minorias e Acesso a Direitos: a Luta por Reconhecimento, a Construção do Self e a articulação de estratégias de promoção de direitos e de resistência frente às instituições e fora delas"

** Discente do sexto período em Direito do Centro Universitário Estácio Juiz de Fora. Pesquisadora discente no Grupo de Pesquisa citado. Correo eletrônico: raquelrqueiroz@hotmail.com

*** Professor de Direito Constitucional no Centro Universitário Estácio Juiz de Fora e Professor Formador CAPES no Centro de Educação à Distância da Universidade Federal de Juiz de Fora. Mestrando em Ciências Sociais pela Universidade Federal de Juiz de Fora. Bolsitas CAPES. Especialista em Direito Público pela PUC-MG, onde também é professor da pós-graduação, atualmente. Correo eletrônico: andreybrugger@hotmail.com
} 
ambos autores em seus textos. Com este fito, pretendemos diferenciar os resultados objetivos do ódio, raiva e culpa, bem como o modo que as agressões invisíveis repercutem na vida do oprimido. Tendo como foco o racismo na vida da "mulher de cor" (expressão utilizada por Lorde para englobar todas as mulheres não brancas) que ainda nos dias de hoje, em uma pirâmide social, se encontram em desvantagem quanto aos demais indivíduos. Faz parte dos objetivos também trazer à tona a reação do oprimido como consequência natural dos séculos de silenciamento, privação e desumanização, analisando os mecanismos institucionais para pacificação social.

Palavras-chave: violência simbólica, opressão, gênero, raça, silenciamento e resposta.

\section{Resumen}

El presente trabajo tiene el objetivo de conectar la teoría creada por Pierre Bourdieu sobre la violencia simbólica y el texto de Audre Lorde, el uso de la expresión: womens responding to racism de su libro Sister Outsider; demostrando la importancia del debate sobre la relación entre dominante y dominado a partir del sesgo racial, tema abordado por ambos autores en sus textos. Con este fin, pretendemos diferenciar los resultados objetivos del odio, la rabia y la culpa, así como el modo en que las agresiones invisibles repercuten en la vida del oprimido. Con el enfoque del racismo en la vida de la "mujer de color" (expresión utilizada por Lord para englobar a todas las mujeres no blancas) que aún en los días de hoy, en una pirámide social, se encuentran en desventaja en cuanto a los demás individuos. Es parte de los objetivos también traer a la superficie la reacción del oprimido como consecuencia natural de los siglos de silenciamiento, privación y deshumanización, analizando los mecanismos institucionales para la pacificación social.

Palabras clave: violencia simbólica, opresión, género, raza, silenciamiento y respuesta. 


\section{Abstract}

The present essay has the objective of connecting the theory created by Pierre Bourdieu on the symbolic violence and the text of Audre Lorde, "The use of anger: women responding to racism" from her book "Sister Outsider"; demonstrating the importance of the debate on the relationship between dominant and dominated from racial bias, a topic addressed by both authors in their texts. For this purpose, we intend to differentiate the objective results of hatred, anger and guilt, as well as the way in which invisible aggressions affect the life of the oppressed. With the approach of racism in the life of the "women of color" (expression used by Lorde to encompass all non-white women) that even today, in a social pyramid, they are at a disadvantage in terms of other individuals. It is part of the objectives also to bring to the surface the reaction of the oppressed as a natural consequence of centuries of silencing, deprivation and dehumanization, analyzing the institutional mechanisms for social pacification.

Keywords: symbolic violence, oppression, gender, race, silence and response. 


\section{INTRODUÇÃO}

Em cuidadosa análise dos aspectos de dominação presentes na sociedade, é perceptível os níveis em que ela se demonstra a partir da colocação de classe social, gênero e raça na qual o sujeito em questão está inserido. Uma vez que se percebe o mundo através dessas camadas, se torna inegável a existência de uma hierarquia secularmente pré-definida onde existem dominantes e dominados. Por consequência, a sociedade foi se edificando em torno dos grupos dominantes, de modo que suas estruturas deveriam servir para garantir privilégios e ao mesmo tempo mantê-los inquestionáveis.

Sabendo disso, este trabalho é um esforço de análise teórica sobre a violência simbólica e opressões sofridas no campo simbólico, físico, emocional e até mesmo institucional. Nessa análise, aparece tanto a parte emocional da opressão e a resposta da raiva, quanto as "heranças" afetivas que permeiam a relação da população negra na sociedade. Nosso principal recorte é o gênero e a raça, interessa-nos o desenvolvimento a partir da situação da mulher negra, tanto no plano dos afetos e do simbólico, quanto o da violência explícita e tratamento institucional.

A naturalização dos privilégios de certos grupos sociais é resultado de intensa construção social, onde padrões são estabelecidos e reafirmados diariamente independentemente do que seja necessário se fazer para tal. É diante deste fato que nos é possibilitado distinguir os tipos de violências em que certos grupos de dominados ${ }^{1}$ estão sujeitos para que sejam mantidos os papéis sociais pré-estabelecidos. Há, portanto, a violência explícita, aquela em que a ação do sujeito dominante está visível e que muitas das vezes é questionada e limitada, seja por normas legais ou morais, que, de certa maneira, é a única a ter contra si um mecanismo de contrapeso que impõe sanções. ${ }^{2}$ E em seu oposto, há a figura da violência simbólica conceituada por Pierre Bourdieu no momento em que abordou a questão da dominação masculina na sociedade e todas as faces em que esta se apresenta.

1 As expressões "dominante" e "dominado" são colocadas com intuito de se aproximar da linguagem utilizada por Pierre Bordieu em sua tese, tendo o mesmo sentido, respectivamente, das expressões "opressor" e "oprimido".

2 É importante salientar que diversas formas de violências explícitas somente foram questionadas e limitadas a partir da conexão da sociedade com seus direitos fundamentais e intrinsecamente humanos. Claro exemplo se faz ao se observar o racismo, cuja análise será realizada no prosseguir do texto. 
Através da tese levantada por Bourdieu, nos é permitido compreender, antes mesmo de conceituar a violência simbólica, que a sociedade, em todos seus aspectos, é direcionada a ter como padrão o que for mais adaptável ao homem, preferencialmente branco e de maiores poderes aquisitivos. E ainda que não gozem de privilégio racial e social, ainda assim, o fator do gênero o garantirá posição hierarquicamente superior a qualquer mulher em mesmas condições.

A partir desta concepção é possível perceber o quão extensa a violência simbólica se manifesta, uma vez que está intimamente ligada a atos do cotidiano que nem sequer ousamos questionar até que ponto poderiam ser naturais ou construídos socialmente. Se manifesta desde as posições sexuais a ocupação da mulher no mercado de trabalho, da linguagem ao poder familiar, dos direitos às obrigações impostas. Consequentemente, ao não gozar de privilégio racial ou social, mais à base da pirâmide de privilégios estas mulheres estão sujeitas.

Portanto, a violência simbólica é, segundo Bourdieu (1998), "violência suave, insensível, invisível a suas próprias vítimas, que se exerce essencialmente pelas vias puramente simbólicas da comunicação e do conhecimento ou, mais precisamente, do desconhecimento, do reconhecimento ou, em última instância, do sentimento".

Este contrato social sobre a hierarquia de privilégios, feito implicitamente, somente ganha forças, segundo esta mesma linha de pensamento, com a adesão do oprimido, o que se considera óbvio, uma vez que não havendo a passividade do dominado, o dominante não teria a oportunidade de gozar de seus privilégios. Desta maneira, resta questionar o que mantém o posicionamento destes grupos frente a constantes violências que somente tem como intuito os colocarem como inferiores, indignos.

Uma vez que a violência simbólica se institui nestes parâmetros, Bourdieu define que, os meios em que o dominado dispõe para se enxergar e enxergar seu dominante, são resultantes de uma incorporação de classificações das quais seu ser social é produto.

Determinar a existência desta adesão, não é, entretanto, um meio de atribuir ao dominado uma responsabilidade sobre sua própria opressão, mas de demonstrar como essas relações de dominação são impostas de maneira sutil, de forma que seja sempre enxergada como natural a existência de um grupo que detém o poder simbólico sobre outro.

Assim, torna-se imprescindível que façamos uma ciência de denúncia. Queremos conceituar com este termo, a epistemologia da compaixão 
e da empatia, que não se furta em problematizar as questões sociais, escancarando-as, abrindo chagas em nossas estruturas e corpos sociais, com o intuito de provar reações para a solução dos problemas enfrentados pela sociedade rumo a uma sociedade político-social mais fraterna e igualitária (objetivo constante na Constituição Federal Brasileira ${ }^{3}$ e em inúmeros instrumentos internacionais de proteção aos direitos humanos ${ }^{4}$ ).

A Ciência de denúncia requer empatia e compaixão. Essa ideia, que construímos a partir do insigh de Martha Nussbaum (2010), demanda que o conhecimento gere nos educandos, nos pesquisadores e no universo que tenha contato com este conhecimento a possibilidade de despertar e treinar a empatia. Empatia significa a habilidade de pensar como é estar no lugar do Outro. Sem dúvidas, este é um passo importante, nada obstante Martha Nussbaum afirma que a empatia não é, por si, suficiente para sedimentar a solidariedade em uma civilização democrática; a Professora exemplifica que os sádicos, os torturadores, os agressores de mulheres, de menores e de homossexuais, também possuem empatia e, por isso mesmo, vangloriam-se muitas vezes de seus atos. A Compaixão, por seu turno, demonstra que é necessário algo mais, a compaixão é o sentimento de que os obstáculos enfrentados pelo Outro são ruins; a Compaixão não exige que nos coloquemos no lugar deste Outro, exige apenas que saibamos que o Outro sofre; sabendo deste sofrimento, tomando consciência deste sofrimento, nós devemos não esconder este sentimento e esta consciência, devemos, isto sim, pensar em atos que possam melhorar as condições de vida deste Outro. Nossa ciência de denúncia tem muito de empatia, mas também a necessária compaixão.

Neste viés, da necessária tomada de consciência e consequente resposta, Audre Lorde apresenta os usos da raiva. O ponto de partida é o grito de uma mulher negra, lésbica e ativista dos direitos civis, em um cenário político pós eliminação das leis de segregação, seguida por um encarceramen-

3 Art. $3^{\circ}$ Constituem objetivos fundamentais da República Federativa do Brasil:

I - construir uma sociedade livre, justa e solidária;

II - garantir o desenvolvimento nacional;

III - erradicar a pobreza e a marginalização e reduzir as desigualdades sociais e regionais;

IV - promover o bem de todos, sem preconceitos de origem, raça, sexo, cor, idade e quaisquer outras formas de discriminação.

4 A Declaração Universal dos Direitos Humanos, principia em sua elaboração o reconhecimento da dignidade inerente a todos os seres humanos, bem como a necessidade de igual tratamento a todos, como se pode observar em seu primeiro artigo o texto: Todas as pessoas nascem livres e iguais em dignidade e direitos. São dotadas de razão e consciência e devem agir em relação umas às outras com espírito de fraternidade. 
to em massa da população negra nos EUA. Ao publicar em 1984 seu livro Sister Outsider, além de se opor aos parâmetros estabelecidos na sociedade, Lorde convoca o questionamento e a necessidade de resposta contrária a essa naturalização, em especial, no texto "Os usos da raiva: mulheres respondendo ao racismo".

Tanto Bourdieu quanto Audre Lorde, demonstram em seus textos a necessidade desta ruptura na relação de "cumplicidade que as vítimas da dominação simbólica têm com os dominantes" através de uma revolução social que tenha a capacidade de oferecer meios para o oprimido se posicionar sobre os processos de desconhecimento deste poder e os parâmetros definidos que o excluem da possibilidade de exercê-lo.

Ao conectar a ideia do poder simbólico e a quebra da relação de dominação a partir do uso da raiva, temos a explosão de uma reação natural do oprimido desencadeada pelos séculos de encarceramento em seu próprio medo e, trazendo esta realidade especificamente para a mulher negra, o uso da raiva sobre seu próprio medo resulta na libertação.

Mulheres respondendo ao racismo significa mulheres respondendo a raiva; raiva da exclusão, dos privilégios não questionados, das distorções raciais, do silêncio, do maltrato, estereotipização, defensividade, má nomeação, traição e captação. Minha raiva é uma resposta às atitudes racistas e às ações e presunção que surgem dessas atitudes

Lorde (1984)

Quando a mulher negra se posiciona contra os privilégios auferidos a seus opressores que, consequentemente, as descaracteriza como ser humano portador de direitos, são obrigadas a aguentar o repúdio de toda sociedade, o que traz novo levantamento: o que leva a se aceitar com passividade a ação do opressor, mas condenar veementemente a reação do oprimido quando este não mais se sujeita aos moldes pré-estabelecidos?

Quando, por exemplo, a mulher negra aponta o racismo em suas manifestações veladas, há a dificuldade da sociedade em estabelecer empatia, uma vez que não o vive diariamente, resultando na relativização de uma opressão, mesmo que ela se apresente de forma estrutural, ao passo que aquele em que teve apontada uma ação racista, recebe da mesma sociedade atos de compreensão. Essa situação é corriqueira. Muitas "piadas" machistas e racistas são direcionadas de maneira opressora às mulheres negras e quando denunciadas, na maior parte das vezes - para não dizermos, de maneira pouco acurada, que na totalidade das vezes -, requer-se "calma" por 
parte da vítima, que ela "veja que o agressor estava 'apenas' brincando". A sociedade parece não ter compreendido, ainda, que as "anedotas" que tragam sofrimento, estereotipização ou sentimento de baixa estima não são humor, são agressões, que impactam diretamente na construção da auto-identidade dessas mulheres. ${ }^{5}$ Conforme aponta Charles Taylor (1994, p. 46), a auto-depreciação gerada pela ideia difundida socialmente da inferioridade é uma das principais armas, se não for a primordial, da persistente dominação.

Nesse aspecto, como compreende Audre Lorde, a única forma de se reagir é com o uso da raiva, não como algo fisicamente violento, mas como uma reação que transcende a isso. A raiva tem o objetivo de poder proporcionar a mulher negra a capacidade de se posicionar na sociedade sem admitir nenhum outro retrocesso que a coloque em desvantagem ou com culpa por estar ocupando espaços que anteriormente não poderia ser admitida.

Raiva é uma reação apropriada para atitudes racistas, como é a fúria quando as ações que surgem daquelas atitudes não mudam. Para aquelas mulheres aqui que temem mais a raiva de mulheres de Cor do que as atitudes racistas não analisadas, eu pergunto: a raiva das mulheres de Cor é mais ameaçadora do que o ódio às mulheres que impacta todos os aspectos das nossas vidas?

Lorde (1984)

A manifestação da raiva das mulheres negras em nenhum momento se equipara ao ódio direcionado a elas por toda sociedade. Diferentemente do que caracterizamos como reação natural do oprimido, o ódio do opressor não é motivado por nada além ser seu pavor de estar sujeito, em algum momento, às mesmas condições de tratamento que há séculos estão impostos a estas mulheres.

5 Uma literatura que dialoga com nossos marcos teóricos eleitos, embora não seja nossa principal fonte de interlocução neste momento, é a teoria do reconhecimento teorizada, dentre outras e outros, por Charles Taylor (1994). Taylor mostra que a exigência do reconhecimento nas sociedades atuais é premente, uma vez que exista uma relação direta entre reconhecimento e identidade. A identidade é compreendida como a maneira como a pessoa se define, como é que suas características fundamentais fazem dela um ser humano. A tese de Taylor está calcada na compreensão de que nossa identidade pode ser em parte formada pela existência ou inexistência de reconhecimento e, muitas vezes, pelo reconhecimento incorreto dos outros, podendo uma pessoa ou um grupo de pessoas serem realmente prejudicadas, sendo alvo de uma verdadeira distorção, se aqueles que os rodeiam refletirem uma imagem limitativa, de inferioridade e até de desprezo por eles mesmos. $\mathrm{O}$ não-reconhecimento ou o reconhecimento incorreto podem afetar negativamente, podem ser uma forma de agressão, reduzindo a pessoa ou o grupo de pessoas a uma forma de ser falsa, distorcida, que as restringem (Taylor, 1994, p. 45). Despiciendo dizer que esse é o quadro que foi, e ainda é, pintado sobre os negros e sobre as mulheres negras: inferioridade, desprezo e restrição. 
O sentimento de ódio que os dominantes direcionam tem poder destrutivo, existente pela incapacidade de perceber o mundo fora de seus privilégios. É o mesmo sentimento que justifica o mito da meritocracia e as demais bandeiras hasteadas pelo senso comum. O caminho do ódio não demanda a saída da zona de conforto nem qualquer tipo de racionalidade, por isso o diferente é facilmente tido como repulsivo, o que faz com que se manifestem as atitudes mais primitivas daqueles que se encontram em posição de poder.

Há séculos as mulheres negras estão limitadas a uma posição às margens da sociedade, sendo obrigadas a lutar por reconhecimentos que aos demais são percebidos como intrínsecos à própria existência. Se o peso de ser mulher já as condena a dominação masculina, o fator racial as tornam invisíveis. Enquanto a mulher branca se organizava na luta para ter, por exemplo, direito ao voto assim como o homem, na mesma época a busca da mulher negra era de simplesmente deixar ser enxergada pela sociedade como objeto de troca, e passar a ser vista como ser humano.

Esse déficit de direitos deve-se à escravidão brasileira, sistema institucionalizado e momento histórico que apresenta as raízes do verdadeiro escárnio social e não-reconhecimento da população negra e das mulheres negras, em especial. A escravidão é aquele fator "negativo" que une a América Latina, uma das principais regiões do Globo receptoras de mão-de-obra escrava negra trazida da África, nos porões de navios ingleses, espanhóis e portugueses.

Com efeito, a escravidão no Brasil começa "oficialmente" na segunda metade do século XVI, com o trabalho escravo dos negros na produção de açúcar. Os Portugueses traziam mulheres e homens negros eram vendidos como mercadorias, sendo os mais saudáveis valendo o dobro. Essa "contabilidade" leva em consideração, por óbvio, aqueles que não morreram nos porões em condições desumanas do navio e que tiveram seus corpos lançados ao mar. Nas fazendas e nas minas de ouro (a partir do século XVIII), trabalhavam em condições desesperadoras, com alta carga laboral (média de 16 horas por dia), recebendo apenas trapos de roupa e alimentação abaixo da quantidade de nutrientes suficientes para uma nutrição razoável. Para além disso, dormiam acorrentados - em uma tentativa do Senhor de Escravo evitar as fugas-, e frequentemente sofriam castigos físicos, sendo o açoite no tronco o mais utilizado. No campo simbólico, também eram açoitados: os escravos eram proibidos de praticarem suas religiões de origens africanas, bem como eram impedidos de realizarem suas festas e rituais. Havia a obri- 
gação de adotar o catolicismo como religião, por imposição dos Senhores, devendo sempre se comunicar em língua portuguesa. Apesar disso, conseguiram manter a tradição africana viva, incorporando, ademais, traços brasileiros, levando ao desenvolvimento de religiões de matriz afro-brasileiras como a umbanda e o candomblé, além de desenvolverem formas de luta como a capoeira.

As mulheres negras também sofreram em demasia no contexto da escravidão. "Oficialmente", o trabalho dessas mulheres eram voltados para os afazeres domésticos, sendo muito comum que fossem utilizadas como cozinheiras, arrumadeiras e até mesmo como amas de leite. Nada obstante, após os "afazeres oficiais", várias eram tomadas, muitas delas contra sua vontade, para satisfação da lascívia sexual dos Senhores, sendo estupradas fisicamente e moralmente. Essas mulheres eram corpos que estavam à mercê dos Senhores, sem qualquer personalidade perante os olhos dessa elite diretiva da economia brasileira de então.

No século XVIII, denominado o século do ouro no Brasil, parte dos escravos conseguia juntar economias e comprar suas próprias liberdades. Nada obstante, ao saírem das fazendas rumo à cidade, encontraram barreiras estruturais e simbólicas como o pouco treinamento em habilidades para o comércio ou outras atividades demandadas pela cidade e, principalmente, a aura social de preconceito contra os negros, que os impediam de desenvolverem suas competências e viver a vida boa após a compra da liberdade.

Também eram comuns as revoltas dos escravos, o grito do oprimido, que fugiam das fazendas rumo aos chamados quilombos. Os quilombos eram lugares em que os escravos viviam em liberdade, eram grupos muito bem organizados, que se autorregulavam de maneira comunitária, nos moldes existentes na África. Nos Quilombos, podiam praticar suas religiões, falar suas línguas e colocar em prática suas culturas.

A partir da metade do século XIX, a escravidão no Brasil passa a ser contestada, inclusive em âmbito internacional. A pressão internacional adveio principalmente da Inglaterra, que estava bastante interessada em ampliar seu mercado consumidor ao redor do Mundo e via no Brasil um potencial País importador. Desta feita, em 1845, o Parlamento Britânico aprova a Lei Bill Abeerden, que proibia o tráfico de escravos e atribuía à Inglaterra o poder de intervir ao redor do mundo no tráfico, ao ponto de os ingleses poderem abordar e apreender navios de outros países que mantivessem essa prática.

Após cinco anos, em 1850, a pressão inglesa surte efeito e o Brasil faz uma lei "para inglês ver", a Lei Eusébio de Queiroz, que deu fim "insti- 
tucional" ao tráfico negreiro. A historiografia brasileira aponta, entretanto, que o tráfico continuou de maneira "pirata" pelo menos por mais dez anos. Seja como for, esse foi o primeiro passo "oficial" rumo ao fim da escravidão no Brasil de maneira oficial ${ }^{6}$. A seguir, em 28 de setembro de 1871, fora aprovada a Lei do Ventre Livere, que dava liberdade aos filhos de escravos nascidos a partir daquela data. Tratou-se, por óbvio, de uma legislação simbólica. Como seria possível uma criança ser verdadeiramente livre se suas principais referências afetivas e físicas, seus pais, continuavam escravos? Será que seria possível que essa criança gozasse de efetiva liberdade simbólica como direito a alimentação, moradia digna, educação, enquanto seus pais permaneciam na senzala? Com efeito, é bom registrar: os Senhores detinham sua tutela até os 21 anos.

Em 1885, foi promulgada a Lei dos Sexagenários. Uma legislação que além de não ter efeitos práticos, é um verdadeiro escárnio institucional. A Legislação garantia a liberdade do escravo que atingisse a idade de 60 (sessenta anos). Contudo, se a expectativa de vida do homem livre girava em torno de 60 a 65 anos, a do escravo estava em torno de 32 a 40 anos (Esteves, 2007), conforme se pode depreender dos registros paroquiais. ${ }^{7}$ Desta forma, eram raros os escravos que atingiram a faixa etária determinada pela Lei; também havia dificuldade do controle etário dos escravos —ainda hoje são muitas as pessoas que não possuem registro de nascimento-. A legislação aliada a essa dificuldade de precisar a idade do escravo gerou a seguinte brecha: caso o escravo estivesse forte, saudável, em boas condições para o trabalho, considerava-se que ele não havia atingido a faixa etária legislativa; de outro modo, caso o escravo se apresentasse fraco, imprestável para o trabalho ou moribundo, fazia-se uso da lei para o dispensar.

6 É relativamente vergonhoso afirmar, mas intelectualmente honesto dizer, que o Brasil ainda possui trabalho escravo em seu território. Essa é uma das grandes batalhas sociais que travamos com o auxílio de órgãos internacionais como a Organização Internacional do Trabalho (OIT).

7 A historiografia brasileira tem mostrado a relevância dos registros paroquiais como fonte de pesquisa documental para a compreensão do período colonial e imperial brasileiro. Os registros paroquiais de batismos, casamentos e óbitos são generalizados a partir do Concílio de Trento, entre os anos de 1545-1563). "No Brasil, a produção dos registros paroquiais assumiu algumas particularidades. Até a instituição da República, em 1889, o clero ocupou lugar de destaque na máquina burocrática do Estado Colonial e Imperial. A constituição de paróquias, a nomeação de padres, a remuneração de parte do clero, dentre outras coisas, eram funções do Estado. Em contrapartida, os padres desempenhavam uma série de papéis como simples funcionários civis. O mais destacado deles era a constituição e controle do sistema de registro de eventos demográficos. Dessa forma, era responsabilidade do clero registrar e coletar informações sobre nascimentos — formalizados por meio do batismo—-, matrimônios e óbitos da população brasileira" (Veloso, 2011, p. 1). 
Em treze de maio de 1888, tem-se oficialmente o fim da escravidão do Brasil, com a assinatura da denominada Lei Áurea, pela Princesa Isabel. A pena da Princesa dava a impressão de que a população negra não mais seria escrava, não sofreria subjugamento, nem exploração, que, enfim, desfrutariam do status de liberdade e igualdade. A Princesa passou para a história como uma personagem forte, atrelada ao direito de liberdade das minorias. Com efeito, as conjunturas políticas e econômicas da época auxiliaram nessa decisão. Em 1888, os negócios calcados na produção açucareira estavam em crise. Isto é, o setor que abrigava $90 \%$ da mão-de-obra escrava passava por uma severa crise sem condições de competir com a produção açucareira de outros países da América Latina, que, além de mais baratos, estavam mais próximos dos mercados consumidores e com açúcar de melhor qualidade que o brasileiro.

Desta maneira, o grande número de escravos, entre homens, mulheres e crianças estavam se tornando um verdadeiro fardo para os Senhores de Engenho, que precisavam gastar com o mínimo de vestuário, alimentação e condições mínimas de moradia. Era preciso continuar mantendo as mercadorias em funcionamento. A solução encontrada foi a demissão em massa. A libertação dos escravos foi, em verdade, uma demissão em massa dos trabalhadores que fizeram existir a economia nacional.

A crueldade está radicada no fato de que esses escravos "libertos" - leia-se: dispensados - não possuíam a opção de ficarem nas fazendas, caso quisessem. Assim, muitos desses escravos tiveram que sair do único local que conheciam por toda uma vida, com suas roupas do corpo e poucos pertences rumo a uma vida sem qualquer preparo ou capacitação para a nova realidade. Em outras palavras, com a demissão em massa travestida de libertação, a quantidade de "livres", dentre os quais os escravos fracos, idosos, doentes e crianças, que não serviam mais aos propósitos dos Senhores, foram enxotados para a rua, sem quaisquer condições materiais e simbólicas. Não houve uma política agrária ou educação formal pública e gratuita para os libertos, como aventavam alguns abolicionistas.

Isto é, com o fim da escravidão, a população negra foi abandonada sem direitos. A chegada da Lei Áurea, não trouxe liberdade aos ex-escravos, apenas os condenaram a um outro tipo de realidade desumana que os mantiveram acorrentados a seus antigos senhores, uma vez que tiveram que continuar a se sujeitar aos mesmos tipos de trabalho em troca de alimento e abrigo.

A questão da democracia racial no Brasil, bem como todos os países que possuem as cicatrizes de uma era escravocrata, é ainda distante nos dias 
de hoje. Tendo em vista que, destes 517 anos desde a colonização portuguesa, aproximadamente $3 / 4$ de sua história é marcada pela escravidão, não há como alegar que as mulheres negras já conquistaram os direitos que lhes foram negados. Os mesmos pressupostos que permitiram a existência da escravização, do abuso sexual e físico destas mulheres, permanecem em nossa sociedade, porém, com outra roupagem.

O preterimento da mulher negra mantém os mesmos moldes de séculos atrás. Não raro estão sujeitas a subempregos, violência policial, violência obstétrica, objetificação e abuso de seus corpos, silenciamento e abandono social.

Assim, quando Lorde trabalha o uso da raiva, nada mais faz do que incentivar as mulheres de cor a não mais compactuar com essa dominação que com o passar do tempo somente se transforma, mas que nunca deixa de existir. É impedir que aquelas que são oprimidas se coloquem em uma posição de culpa, pois na culpa não há revolução, somente mais uma resposta para impotência.

Culpa não é uma resposta à raiva; é uma resposta à ação ou falta de ação de alguém. Se leva à mudança, então pode ser útil, já que não é mais culpa e sim começo de conhecimento. Ainda assim, muito frequentemente, culpa é apenas mais uma resposta para impotência, para defensividade destrutiva de comunicação; se torna uma ferramenta para proteger a ignorância e a continuação das coisas como são, a mais nova proteção da falta de mudança

Lorde (1984)

Ao trazermos esse discurso para os dias atuais, percebemos que, para além da atuação do movimento social negro e feminista, há a necessidade de fazer com que aqueles que ocupam os locais de privilégio também se questionem (criação da empatia somada a compaixão). E ainda que o uso da raiva modifique a forma que a mulher de cor entenda seu lugar na sociedade, não é capaz de sozinho, modificar as estruturas que mantém as relações de poder.

Para que seja possível incutir nos grupos dominante a empatia e compaixão necessária para revolução e modificação do status social que as mulheres negras estão subordinadas, o meio utilizado deverá ser a educação. Não há como se desprender da necessidade de um ensino libertador quando se aborda as questões de desigualdade social. Assim como os meios de dominação se construíram e foram repassados através dos séculos por meio de uma doutrinação também reproduzida nos meios educacionais, é também por este meio que há de se iniciar a sua destruição. A única forma de cons- 
truir novos conceitos é abrindo mão do que se conhece e se aplica nos dias atuais.

\section{ABORDAGEM DO SISTEMA DE COTAS RACIAIS}

Não basta a mulher negra ter conhecimento do que lhe é negado e o histórico de como isto se consolidou, é indispensável que a sociedade pare de lutar contra essas mulheres sem dar a elas armas que possibilitem vencer. Não há vencedor em uma luta que não pode ser vencida. A sociedade obriga que as mulheres de cor sempre se prove acima do restante da população para poder ser reconhecida, o que se pode traduzir nos versos do rimador e detentor uma das vozes mais importantes no cenário rap nacional, Pedro Paulo Soares Pereira, o Mano Brown, "como fazer duas vezes melhor, se você está pelo menos cem vezes atrasado pela escravidão, pela história, pelo preconceito, pelos traumas?".

Para a emancipação da mulher negra, paralelamente a abordagem educacional, existem as políticas públicas, que permitem através da transferência de renda a colocação dessas mulheres em ascensão social. É necessário dar destaque a estes meios alternativos

\section{REFERÊNCIAS}

Bordieu, P. (2016). A dominação masculina: A condição feminina e a violência simbólica. Rio de Janeiro: Edições Bestbolso.

Esteves, A. (2007). O 13 que a História não contou. Recuperado de http://www.overmundo.com.br/overblog/o-13-que-a-historia-nao-contou

Lorde, A. (1984). The use of anger: womens responding to racism. In Sister Outsider (págs. 124-133). Toronto: Crossing Press.

Nussbaum, M. C. (2010). Sin fines de lucro: por qué la democracia necesita de las humanidades. Madrid: Katz.

Taylor, Ch. (1994). A Política de Reconhecimento. In Multiculturalismo: examinando a política de reconhecimento. Lisboa: Instituto Piaget.

Veloso, L. F. (2011). Expectativa de vida e Mortalidade de escravos: Uma análise da Freguesia do Divino Espírito Santo do Lamim - MG (18591888). Histórica - Revista Eletrônica do Arquivo Público do Estado de São Paulo, 51. 